\title{
Application value of magnetic resonance hydrography of the inner ear in cochlear implantation
}

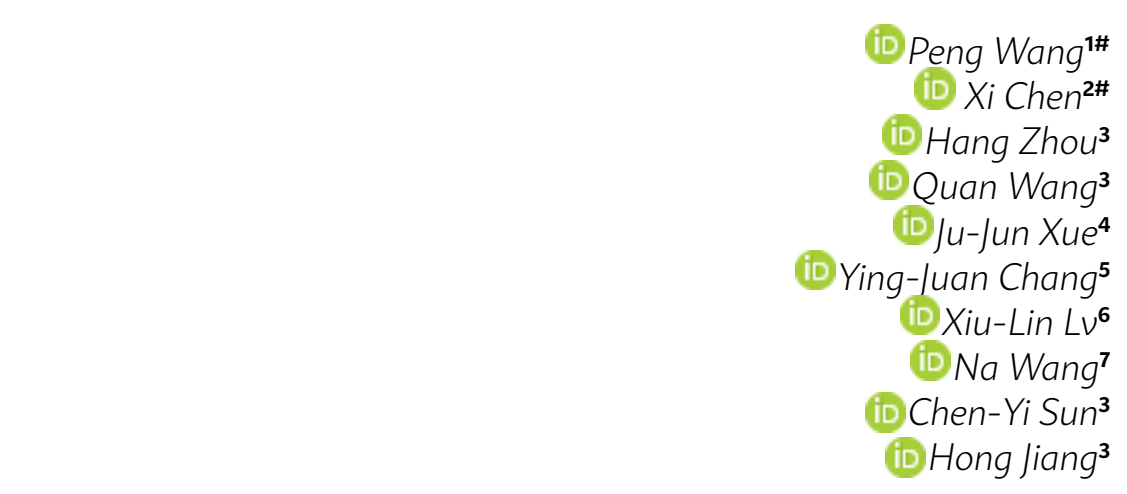

1. Integrated $T C M$ \& Western Medicine Department, Heilongjiang Provincial Hospital, Harbin, 150036 , China 2.Department of radioimmunity, Heilongjiang Provincial Hospital, Harbin, 150036, China 3.Department of magnetic resonance imaging, Heilongjiang Provincial Hospital, Harbin, 150036, China 4.Geriatric department of Internal Medicine, Heilongjiang Provincial Hospital , Harbin, 150036,China 5.Central supply room, Heilongiiang Provincial Hospital, Harbin 150036, China 6.Quality Control Office, Heilongjiang Provincial Hospital, Harbin 150036, China 7.Medical Administration Division, Heilongjiang Provincial Hospital, Harbin 150036, China \# Peng Wang and Xi Chen contributed to this paper equally, both as the first authors.

http://dx.doi.org/10.1590/1806-9282.66.1.74

\section{SUMMARY}

OBJECTIVE: This study aims to investigate the application value of magnetic resonance $(M R)$ hydrography of the inner ear in cochlear implantation.

METHODS: 146 patients were enrolled. MR hydrography and spiral CT examinations for the intracranial auditory canal were performed before surgery, and all imaging results were statistically analyzed in order to explore the application value of MR hydrography of the inner ear in cochlear implantation.

RESULTS: 146 patients (292 ears) were examined. Among these patients, 13 were diagnosed with abnormal vestibular aqueducts (20 ears) by MR hydrography, while five were diagnosed with this disease by CT; 15 patients were diagnosed with inner ear malformation (19 ears) by MR hydrography, while 11 were diagnosed by CT (four were misdiagnosed); five patients were diagnosed with internal acoustic canal stenosis (eight ears) by MR hydrography, while two were diagnosed by CT (three were misdiagnosed); and four patients were diagnosed with cochlear fibrosis (five ears) by MR hydrography, while four were diagnosed by CT (four ears). The correct rate of diagnosis was $77.40 \%$ (113/146) based on CT, while the rate was 93.84\% (137/146) based on MR hydrography.

CONCLUSIONS: MR hydrography imaging technique can be applied to the preoperative evaluation of cochlear implantation, providing accurate and reliable anatomic information on the inner membranous labyrinth and nerves in the internal acoustic canal and an accurate basis for the diagnosis of cochlear fibrosis and nerve development. This has a guiding significance for the selection of treatment schemes.

KEYWORDS: Magnetic Resonance Hydrography of Inner Ear Imaging; Cochlear Implants; Clinical Application Value.

DATE OF SUBMISSION: 05-Aug-2019

DATE OF ACCEPTANCE: 01-Oct-2019

CORRESPONDING AUTHOR: Hang Zhou

Department of magnetic resonance imaging, Heilongjiang Provincial Hospital, No.82 of Zhongshan Road ,Xiangfang District, Harbin

150036, China - Tel: +86 45187131060 - Fax: +86 45187131060

E-mail:26276486@qq.com 


\section{INTRODUCTION}

Cochlear implantation (CI) is the most effective means of rehabilitation for patients with severe and very severe sensorineural hearing loss. Preoperative imaging examination is the basis for understanding the condition and characteristics of important anatomical regions related to surgery. ${ }^{1} \mathrm{CI}$ requires the surgeon to have enough and detailed understanding on the structures and pathological changes in the inner ear of patients, develop a comprehensive treatment scheme, and select the most suitable electronic cochlear implant and electrode before surgery. ${ }^{4}$ Surgeons need to ensure the presence of inflammation and mastoid gasification, morphology, patency, and basal turn of the cochlea in the inner ear by imaging tests. However, due to limited density resolution, spatial resolution and other technical factors, traditional plain X-ray films and spiral CT (computerized tomography) examinations could not clearly and accurately display changes of the structure and function of the membranous labyrinth in the inner ear ${ }^{5}$, and could not provide accurate and reliable information for the preoperative evaluation of CI.

MR hydrography images use the static or slowly flowing fluids in the body, so the imaging mainly consists of fluid-containing structures. MR hydrography exhibits hyperintense signals mainly through the T2 relaxation values of water, while the $\mathrm{T} 2$ relaxation values of the surrounding tissues show hypointense signals. Thus, this improves the resolution of the MRI device on tissues. The T2 relaxation value of water is higher than that of other tissues in the human body, and the T2WI sequence where the weight of $\mathrm{T} 2$ is very heavy can make the transverse magnetization vector of other tissues close to the total loss. Hence, signals could not be collected, while the long $\mathrm{T} 2$ relaxation value of water can maintain a large value of the transverse magnetization vector. Therefore, the signals collected by MRI are mainly from water structures with large transverse magnetization vector values. ${ }^{6}$ This is the hydrography (water imaging) technology. Compared with MRI, it does not need direct or intravenous contrast, and it is very suitable for the imaging of fluid-containing structures ${ }^{6}$.

Magnetic resonance (MR) hydrography of the inner ear adopts special imaging technology that focuses on signals on the water to clearly display the fine and complex structures contained in it, such as the internal labyrinth structure, internal acoustic canal, and vestibulocochlear nerve. Hence, it is of great value for the preoperative evaluation of CI. ${ }^{2}$ Conventional cochlear implant is a surgical procedure performed on the posterior tympanum through a transmastoid facial recess approach that opens the facial nerve recess and exposes the round window niche and round window membrane. Finally, the electrode is implanted into the cochlea tympanic canal. On account of narrowness and large variations in the anatomical structure of the facial recess, it frequently presents tremendous difficulties and increasing lesion risks to the tympanum and facial nerves. Therefore, the observation and assessment by preoperative fossa temporal scanning are of great significance. Prof. Xuebin He et al. measured facial recess sizes and made a comparative analysis based on anatomical data ${ }^{15}$. The results revealed there was no statistical variation between them. It is deemed that the fossa temporal contributed to preoperative observing and measuring the facial recess size; the structures involved were the pyramid segment of the facial nerve, posterior wall of external auditory foramina, fenestra cochleae, and osseous labyrinth, which in the normal inner ear could be vital anatomic landmarks for operation reference.

However, despite the complicated and meticulous structures of the osseous labyrinth in the normal inner ear and other nerves as well as its deep position in the petrous bone, it is difficult to identify and probe the lesions in detail. The effects of conventional CT detection are not acceptable for diseases in the internal ear, including cochlear fibrosis, congenital malformation, and neuropathy. We have been trying to use 3D-FIESTA-C high spatial resolution and SNC (Sun Nuclear Corporation) as well as clear images of blood vessels and nerves, to measure the facial recess size associated with HDCT (high definition computerized tomography) scan. It not only clearly displayed both the inner ear labyrinth artery and nervus vestibulocochlear but also revealed the association between them. ${ }^{3}$

In this study, the application value of MR hydrography of the inner ear in cochlear implantation was evaluated. Details are reported as follows.

\section{METHODS}

Clinical data

After screening, 146 patients who underwent CI in our hospital from January 2012 to January 2014 were enrolled in this study. Among them, 85 were male, and 61 were female; their ages ranged from eight months 
to 49 years (average: $6.5 \pm 1.6$ years). Among these patients, 112 had congenital sensorineural hearing loss, nine had drug-induced deafness, 15 had postlingual deafness, and 10 had unexplained deafness. All patients were confirmed with bilateral severe sensorineural hearing loss by audiological examination and received CI. Furthermore, 82 patients chose implantation on the right side, and 64 chose it on the left side. Moreover, 68 patients were implanted with a Nucleus $24 \mathrm{M}$ contour electrode, 21 with a $90 \mathrm{~K}$ artificial cochlea (AB, USA), 25 with a Combi-40 cochlear implant (Med-EL), 16 with a Pusal implant, and 32 with a CS-10A implant (Nuoerkang).

\section{Experimental methods}

Data were collected before surgery. Routine audiological examinations were initially performed: all patients underwent brainstem auditory-evoked potentials (BAEP), otoacoustic emission (OAE), acoustic impedance, and auditory steady-state response (ASSR); and the 40-Hz auditory event related potential (AERP) and brainstem electric response audiometry (BERA) could be additionally performed. Adult patients with postlingual deafness needed to undergo BERA independently. Audiological examinations revealed that all patients had preoperative $\geq 95 \mathrm{~d}$ Bn HL, and did not elicit bilateral OAE, while some patients elicited ASSR.

Next, MR hydrography was performed. Patients were placed in the supine position, the skull was placed in the middle, and both ears were kept symmetrically. Children with good cooperation did not require special surgeries. For infant patients, doctors asked the family to help the infants to fall asleep more easily or gave the infant sedation before the examination. Examinations were performed using the 3.OT GE Signa HDx MRI scanner in our hospital. The head of the patient was fixed with an 8-channel head array coil for MRI. The range of scanning included the petrous part and the head of the temporal bone. A three-dimensional fast advanced spinecho (FASE) sequence was used to scan the region of interest transversely. The parameters of hydrography scanning of the inner ear were set as follows: slice thickness was set at $0.8 \mathrm{~mm}$, the gap between slices at $0.4 \mathrm{~mm}$, the number of slices at $64, \mathrm{TE}$ at $2.5 \mathrm{~ms}$, TR at $6.5 \mathrm{~ms}$, FOV at $16 \times 16 \mathrm{~mm}$, and the scan matrix was set at $512 \times 256$. MRI image data were acquired twice. The original MRI images of the temporal bone were three-dimensionally reconstructed using an image processing software with maximum intensity projection (MIP). Next, the MIP hypointense signals of the surrounding tissues around the inner ear were cleared off using the workstation software. Finally, only the image of the region of interest was retained. The three-dimensional hydrography images of the inner ear in multiple axial planes were acquired by rotating the images $30-180^{\circ}$.

Thin-slice CT scanning of the temporal bone was performed using the GE Hi-speed spiral CT in our hospital. More attention was given to the patient's vestibular aqueduct, facial nerve, semicircular canal, vestibule, and cochlea during scanning. Scanning parameters were set as follows: slice thickness was set at $1.0 \mathrm{~mm}$, the gap between slices at $1.0 \mathrm{~mm}$, tube voltage at $120 \mathrm{kV}$, tube current at $200 \mathrm{~mA}$, window width at 3,500 $\mathrm{HU}$, and the window was set at $500 \mathrm{HU}$.

\section{Diagnostic criteria}

MRI diagnostic criteria

(1) Large Vestibular Aqueduct Syndrome

Reflected by the enlargement of the saccus lymphaticus, i.e., the maximum width of the midpoint of the internal part of the endolymphatic sac bone greater than $1.5 \mathrm{~mm}$.

(2) Cochlear malformation

The absence of the cochlea, vestibule, or semicircular canal is reflected by the hyperintensity in the imaging.

(3) Narrowed internal auditory canal

Reflected by the narrow diameter of the internal auditory canal, which is $<2 \mathrm{~mm}$.

(4) Fibrosis of the cochlea

Reflected by the decreased hyperintensity and the asymmetrical signal of the cochlea.

\section{CT criteria}

(1) Large Vestibular Aqueduct Syndrome

Reflected by the enlargement of the middle of the vestibular aqueduct (greater $2 \mathrm{~mm}$ ).

(2) Cochlear malformation

The absence of the cochlea, vestibule, or semicircular canal is reflected by the high density in the imaging.

(3) Narrowed internal auditory canal

Reflected by the narrow diameter of the internal auditory canal, which is $<2 \mathrm{~mm}$.

(4) Fibrosis of the cochlea

Reflected by the increased density of the cochlea. 


\section{Statistical processing}

Statistical analysis was performed using IBM SPSS19.0 statistical software. Measurement data were expressed as mean \pm standard deviation $(\overline{\mathrm{x}} \pm \mathrm{SD})$ and were evaluated using the $t$-test. Count data were evaluated using the $X^{2}$-test. The inspection level was set as $\alpha=0.05 . P<0.05$ was considered statistically significant.

\section{Results}

Among the 146 patients (292 ears), 95 were confirmed with abnormal ears by surgical treatment. Among these, 13 patients were diagnosed with abnormal vestibular aqueducts (20 ears) by MRI, while five were diagnosed with this disease by CT; 15 patients were diagnosed with inner ear malformation (19 ears) by MR hydrography, while 11 were diagnosed by CT (four were misdiagnosed); five patients were diagnosed with internal acoustic canal stenosis (eight ears) by MR hydrography, while two were diagnosed by CT (three were misdiagnosed); and four patients were diagnosed with cochlear fibrosis (five ears) by MR hydrography, while four were diagnosed by CT (four ears). The correct rate of diagnosis was $77.40 \%$ $(113 / 146)$ based on CT, while this rate was $93.84 \%$ (137/146) based on MR hydrography.

\section{Comparison of the results of spiral CT and MR} hydrography in all patients

Detection results of abnormal ears by spiral CT, MR hydrography, and combined examination were acquired and compared. The results are shown in Table 1.

Table 1 shows that the differences in detection rates between spiral CT and MR hydrography, and between spiral CT and combined examination, were statistically significant $(P<0.05)$. In addition, the MRI differences in the detection rate between MRI and CT, or between MRI and combined examination, were not statistically significant $(P>0.05)$.

\section{Comparison of the detection results of abnor-} mal ears by $C T$ and MRI

Imaging detection results of abnormal ears by CT and MRI were collected and compared. These results are shown in Figure 1. Figure 1 shows that the differences in detection rates between MRI and spiral CT, and between combined examination and spiral CT, were statistically significant $(P<0.05)$.

Comparison of detection rate of cochlear malformation and inner ear canal stenosis by CT and MRI

According to the results of both imaging methods, the detection rates of cochlear malformation and inner ear canal stenosis were collected. The results are shown in Table 2. Table 2 shows that the difference in the diagnostic accuracy of cochlear malformation and stenosis of the inner ear canal between CT and MRI was statistically significant $(P<0.05)$.

\section{DISCUSSION}

The internal tissues of the membranous labyrinth in the human inner ear are full of lymph, and the internal acoustic canal is full of cerebrospinal fluid. Therefore, the detection of internal tissues of the membranous labyrinth and internal acoustic canal in the inner ear is strongly sensitive using MR hydrography. Hence, this can collect strong signals and is not affected by hypointense signals from the surrounding bony structure ${ }^{7}$, thereby allowing the clear and accurate acquisition of images.

TABLE 1. COMPARISON OF THE RESULTS OF SPIRAL CT AND MR HYDROGRAPHY IN ALL PATIENTS

\begin{tabular}{|c|c|c|c|c|c|c|}
\hline \multirow[t]{2}{*}{ Imaging manifestations } & \multicolumn{2}{|c|}{ Abnormal results of spiral CT } & \multicolumn{2}{|c|}{$\begin{array}{l}\text { Abnormal results of MR hydrog- } \\
\text { raphy }\end{array}$} & \multicolumn{2}{|c|}{$\begin{array}{l}\text { Abnormal results of spiral CT } \\
\text { combined with MR hydrography }\end{array}$} \\
\hline & Cases (ear) & Rate (\%) & Cases (ear) & Rate (\%) & Cases (ear) & Rate (\%) \\
\hline Cochlear malformation & 11 & 3.77 & 19 & 6.51 & 21 & 7.19 \\
\hline Internal auditory canal stenosis & 3 & 1.03 & 8 & 2.74 & 10 & 3.42 \\
\hline Cochlear fibrosis and ossification & 4 & 1.37 & 5 & 1.71 & 5 & 1.71 \\
\hline $\begin{array}{l}\text { Enlargement of the vestibular } \\
\text { aqueduct }\end{array}$ & 7 & 2.40 & 20 & 6.85 & 21 & 7.19 \\
\hline Chronic otitis media & 5 & 1.71 & 19 & 6.51 & 20 & 6.85 \\
\hline Exposed facial nerve & 2 & 0.68 & 10 & 3.42 & 10 & 3.42 \\
\hline Total abnormal ears & 31 & 10.62 & 81 & 27.74 & 87 & 29.79 \\
\hline
\end{tabular}

Note: Rate $=$ abnormal ears $/$ total ears; Degree of freedom $=3$ 
It was found that the preoperative imaging test is the only method that can objectively evaluate the conditions and characteristics of the essential anatomic regions related to surgery because accurate imaging of the structures and functions of the membranous labyrinth in the inner ear helps the surgeon select the most appropriate treatment and artificial cochlea electrode ${ }^{8}$. Among these, the test results of acute and chronic OM, internal acoustic canal malformation, cochlear malformation, and fibrous ossification can provide the most accurate indications for the surgeon. Spiral CT has a higher resolution in bone structure and ossification; therefore, its detection rates of bony development and lesions in the inner ear are high ${ }^{9}$. However, limited by density resolution, spiral CT could only acquire images of bony lesions in the bony labyrinth and internal acoustic canal; it has difficulty in acquiring images of soft tissue, cochlear membranous labyrinth, and fibrosis. Since the membranous labyrinth's internal acoustic canal in the inner ear are full of lymph fluid and cerebrospinal fluid, the MR hydrography technique could accurately evaluate structural changes in the membranous labyrinth and internal acoustic canal by acquiring the images of the shapes and distribution of the lymph fluid inside and outside ${ }^{10}$. Specific MRI signs could be used for the preoperative evaluation of surgical indications: under normal condition, MRI image of the internal acoustic canal exhibits cone- and tube-shaped hyperintense signals and hyperintense cerebrospinal fluid signals. The courses and gaps of vessels and nerves are definite. The cochlea exhibits a typical spiral snail-like shape, and the alveus utriculosus and saccule are integral, exhibiting a hyperintense signal. The semicircular duct exhibits a C shape, and its

FIGURE 1. $X^{2}$-TEST OF THE DETECTION RESULTS OF ABNORMAL EARS BY CT AND MRI.

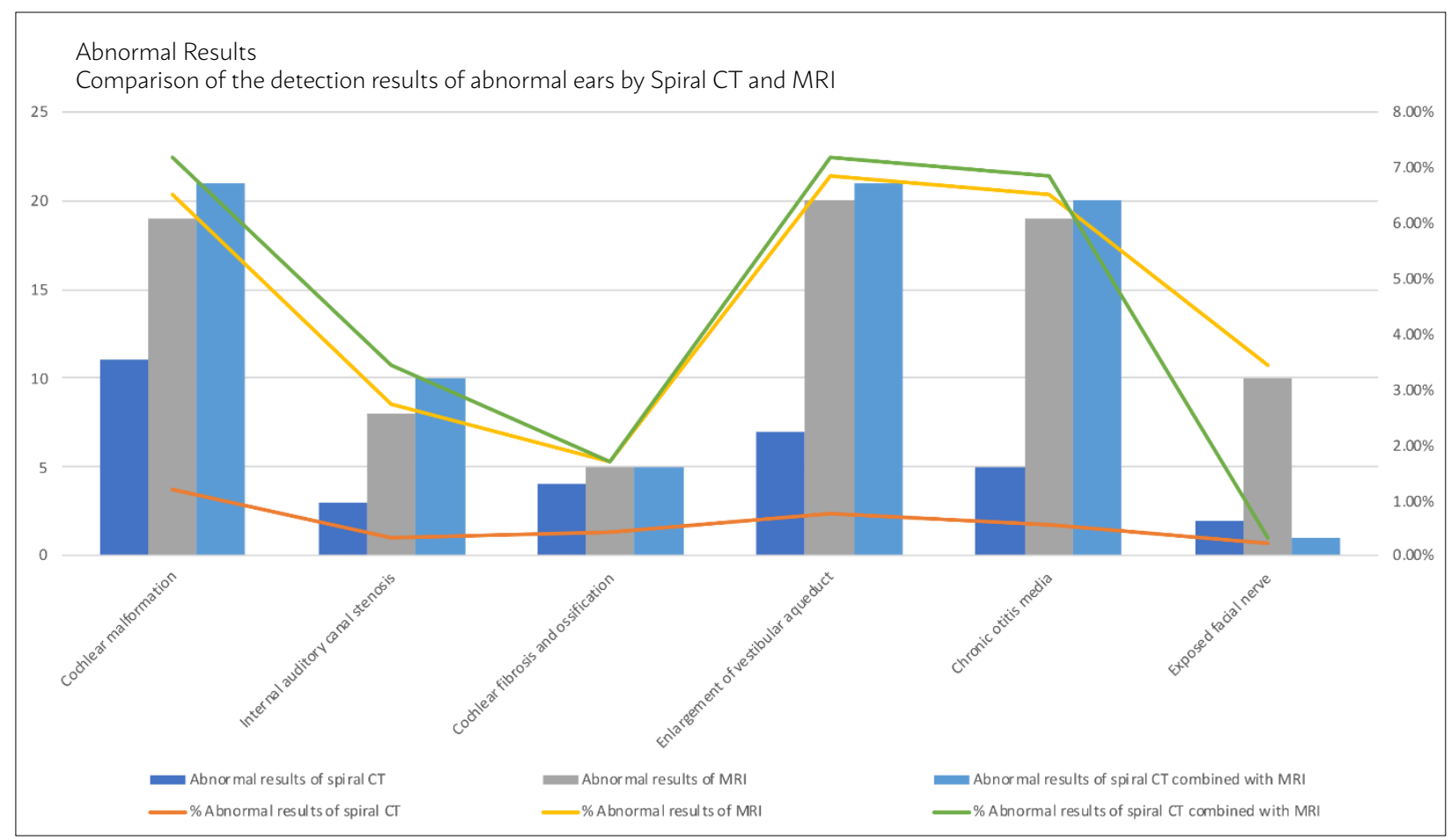

The inspection level was set at $\alpha=0.05$. $P<0.05$ was considered statistically significant; Degree of freedom $=3$

TABLE 2. COMPARISON OF THE DETECTION RATE OF COCHLEAR MALFORMATION AND INNER EAR CANAL STENOSIS BY CT AND MRI

\begin{tabular}{|c|c|c|c|c|c|}
\hline Imaging manifestations & $\begin{array}{l}\text { Abnormal results of } \\
\text { spiral CT (percentage in } \\
\text { Abnormal results of spiral } \\
\text { CT combined with MR } \\
\text { hydrography) }\end{array}$ & $\begin{array}{l}\text { Abnormal results of MRI } \\
\text { (percentage in Abnor- } \\
\text { mal results of spiral } \\
\text { CT combined with MR } \\
\text { hydrography) }\end{array}$ & $\begin{array}{l}\text { Total number of abnor- } \\
\text { mal ears detected by } \\
\text { spiral CT combined with } \\
\text { MR hydrography }\end{array}$ & $\chi^{2}$ & $P$ \\
\hline Cochlear malformation & $11(52.38 \%)$ & $19(90.48 \%)$ & 21 & 145.326 & $<0.001$ \\
\hline $\begin{array}{l}\text { Internal auditory canal } \\
\text { stenosis }\end{array}$ & $3(27.27 \%)$ & $8(72.73 \%)$ & 11 & 5.699 & 0.019 \\
\hline
\end{tabular}


margins are smooth. ${ }^{11}$ Under pathological conditions, the MRI performance of dysplasia and malformation of the inner ear is the absence of corresponding images. Generally, these were Michel and Mondini malformations. ${ }^{12}$ The vestibular aqueduct syndrome mostly exhibits as abnormal hyperplasia of the endolymphatic duct and saccus lymphaticus, which shows hyperintense signals. Furthermore, attention should be paid in examining the cochlear nerve during the preoperative examination. A clinical trial confirmed that lesions in the cochlear nerve were the absolute contraindication in CI. ${ }^{13}$ Spiral CT could not accurately evaluate whether the structure of the cochlear nerve changes, while the correct diagnostic rate of MR hydrography for cochlear nerve lesions is relatively high, showing the changes of the neural structure in the internal acoustic canal. ${ }^{14}$ This has important significance for determining surgical indications.

MRI demonstrates the shape of the inner ear screened by the water composition. It is confirmed that the observed effect by MRI is worse than CT; while referring to the detection of mastoiditis, MRI is similar to CT. The comprehensive imaging of both endolymph and perilymph was captured by three-dimensional reconstructed MRI, without the bone composition. It is equivalent to three-dimensional reconstruction imaging by $\mathrm{CT}$, excluding subjective dependence. The display of the cochlear duct, scala vestibule, and semicircular ducts is much better than CT. Besides, MRI is much more sensitive to detect the effect of fibro ossification of the internal and accurate to estimate pathological lesions than CT. Therefore, we believe that the three-dimensional reconstruction imaging evaluation method by MRI for use concerning the inner ear provided many more advantages compared to the single three-dimensional reconstruction by CT. In addition, the preoperative assessment provided a necessary reference value as a surgical supplement.

The limitation of the study is mainly its relatively small sample size since there are many kinds of abnormalities. A larger sample size can lead to more important results and conclusions.

\section{CONCLUSION}

In summary, the MR hydrography technique can be applied to the imaging evaluation before CI, providing accurate and reliable anatomic information regarding nerves in the membranous labyrinth and internal acoustic canal of the inner ear. Furthermore, it provides an accurate basis for the diagnosis of cochlear fibrosis and nerve development and has a guiding significance for the selection of treatment schemes.

\section{Funding}

Fund program: Research project of Heilongjiang provincial health and Family Planning Commission(No. 2016-541), (No:2018416), (No:2019163).

\section{List of Abbreviations}

Magnetic Resonance: MR

Cochlear Implantation: CI

Otoacoustic Emission: OAE

Auditory Steady-State Response: ASSR

Auditory Event-Related Potential: AERP

Brainstem Electric Response Audiometry: BERA

Fast Advanced Spin Echo: FASE

Sensorineural Hearing Loss: SNHL

\section{Author Contributions}

All authors contributed equally to the work.

\section{RESUMO}

OBJETIVO: Este estudo visa investigar o valor da aplicação da hidrografia por ressonância magnética (RM) do ouvido interno no implante coclear.

MÉTODOS: Cento e quarenta e seis pacientes foram inscritos. Os exames da hidrografia por RM e do CT espiral para o canal auditivo intracraniano foram executados antes da cirurgia, e todos os resultados da imagem foram analisados estatisticamente, a fim de explorar o valor da aplicação da hidrografia por RM do ouvido interno no implante coclear.

RESULTADOS: Centro e quarenta e seis pacientes (292 ouvidos) foram examinados. Dentre esses pacientes, 13 foram diagnosticados com aquedutos vestibulares anormais (20 ouvidos) pela hidrografia por RM, enquanto cinco pacientes foram diagnosticados com esta doença pelo CT; 15 pacientes foram diagnosticados com malformação do ouvido interno (19 ouvidos) pela hidrografia por RM, enquanto 11 pacientes foram diagnosticados por CT (quatro foram diagnosticados erroneamente); cinco pacientes foram diagnosticados com estenose de canal acústico interno (oito ouvidos) pela hidrografia por RM, enquanto dois pacientes foram diagnosticados por CT (três foram diagnosticados erroneamente); e quatro pacientes foram diagnosticados com fibrose coclear (cinco ouvidos) pela hidrografia por RM, enquanto quatro foram diagnosticados por CT (quatro ouvidos). A taxa correta de diagnóstico foi de 77,40\% (173/146) com base no CT, enquanto a taxa foi de 93,84\% (137/146) com base na hidrografia por RM. 
CONCLUSÕES: A técnica de imagem da hidrografia por RM pode ser aplicada à avaliação pré-operatória do implante coclear, que pode fornecer informações anatômicas precisas e confiáveis sobre o labirinto membranoso interno e os nervos no canal acústico interno, além de uma base exata para o diagnóstico da fibrose coclear e do desenvolvimento do nervo. Isso tem um significado orientador para a seleção de esquemas de tratamento.

PALAVRAS-CHAVE: Hidrografia por ressonância magnética da imagem do ouvido interno. Implantes cocleares. Valor da aplicação clínica.

\section{REFERENCES}

1. Jerger J. Bilateral cochlear implantation. J Am Acad Audiol 2010; 21(4): 224.

2. Jara H, Barish MA, Yucel EK, Melhem ER, Hussain S, Ferrucci JT. MR hydrography: theory and practice of static fluid imaging. AJR Am J Roentgenol. 1998; 170(4):873-82.

3. van den Boogert T, van Hoof M, Handschuh S, Glueckert R, Guinand N, Guyot JP, Kingma H, Perez-Fornos A, Seppen B, Johnson Chacko L, SchrottFischer A, van de Berg R. Optimization of 3D-Visualization of Micro-Anatomical Structures of the Human Inner Ear in Osmium Tetroxide Contrast Enhanced Micro-CT Scans. Front Neuroanat. 2018;12:41.

4. Ozeki M, Kato Z, Sasai H, Kubota K, Funato M, Orii K, Kaneko H, Fukao $T$ and Kondo N. Congenital inner malformations without sensorineural hearing loss in children. Int J Pediatr Otorhinolaryngol 2009; 73(10): 1484-7.

5. Loundon N. Pathophysiology and genetics of deafness. Arch Pediatr2006; 13(6): 772-4

6. Kline-Fath BM, Calvo-Garcia MA, O'Hara SM, Racadio JM. Water imaging (hydrography) in the fetus: the value of a heavily T2-weighted sequence. Pediatr Radiol. 2007;37(2):133-40.

7. Xue T, Qiu JH, Wei L, Qiao L, Lu LJ, Chen Y, Zha DJ, Wen LT and Lou $\mathrm{H}$. Bilateral cochlear implantation: advantages and disadvantages. Otol Neurotol 2009; 30(5): 690.
8. Wienke A and Janke K. Legal aspects of cochlear-implantation. Laryngorhinootologie 2007; 86(9): 664-5.

9. Wei BP, Clark GM, O'Leary S), Shepherd RK and Robins-Browne RM. Meningitis after cochlear implantation. BMJ 2007; 335(7629): 1058.

10. Han De-min. The emerging field of cochlear implantation in China. Zhonghua Er Bi Yan Hou Tou Jing Wai Ke Za Zhi 2006; 41(12): 881-2.

11. Raz Y. The utility of the MAUDE database in researching cochlear implantation complications. Arch Otolaryngol Head Neck Surg 2005; 131(3): 251.

12. Helms J, Müller J, Brill S, Schön S and Shehata-Dieler W. Modern cochlear implantation. Otolaryngol Pol 2005; 59(6): 803-5.

13. Graham JM, Phelps PD and Michaels L. Congenital malformation of the ear and cochlear implantation in children: Review and Temporal bone report of common cavity. J Laryngol Otol Suppl2000; 25: 1-14.

14. Schmidt AM, Weber BP, Vahid M, Zacharias R, Neuburger J, Witt M, Lenarz $T$ and Becker $\mathrm{H}$. Functional M R imaging of the auditory cortex with electrical stimulation of the promontory in 35 deaf patients before cochlear implantation. AJNR Am J Neuroradiol 2003; 24(2): 201-7.

15. He X, Feng Y, Chen DM, Mei LY, He CF, Cai XZ. Study of the anatomy related to cochlear implantation guided by HRCT. JClin Otorhinolaryngol Head Neck Surg (China) 2011; 25 (1): 433-5. 
Regarding the article "Application value of magnetic resonance hydrography of the inner ear in cochlear implantation" with DOI number: http:// dx.doi.org/10.1590/1806-9282.66.1.74, published in Journal of the Brazilian Medical Association, 2020;66(01), page 74, authors name order, affiliation and Corresponding Author info in the article changed from:

\section{Authors:}

Quan Wang

Hang Zhou ${ }^{1}$

Peng Wang ${ }^{2}$

Ju-Jun Xue

Ying-Juan Chang ${ }^{4}$

Xiu-Lin $L v^{5}$

Na Wang ${ }^{6}$

Chen-Yi Sun ${ }^{1}$

Hong Jiang ${ }^{1}$

\section{Affiliations}

1. Department of Medical Imaging, Heilongjiang Provincial Hospital, Harbin, 150036, China.

2. Integrated TCM \& Western Medicine Department, Heilongjiang Provincial Hospital, Harbin, 150036, China.

3. Geriatric Department of Internal Medicine, Heilongjiang Provincial Hospital, Harbin, 150036, China.

4. Central Supply Room, Heilongjiang Provincial Hospital, Harbin 150036, China.

5. Quality Control Office, Heilongjiang Provincial Hospital, Harbin 150036, China.

6. Medical Administration Division, Heilongjiang Provincial Hospital, Harbin 150036, China.

\section{Corresponding Author}

CORRESPONDING AUTHOR: Quan Wang

Department of medical imaging, Heilongjiang Provincial Hospital, n.82 of Zhongshan Road, Xiang-

fang District, Harbin, China - 150036

Tel: +86 45187131061 / Fax: +86 45187131061

E-mail:wq_doc16@163.com

\author{
To Authors \\ Peng Wang" \\ (iD) XiChen ${ }^{2 \#}$ \\ Hang Zhou ${ }^{3}$ \\ Quan Wang ${ }^{3}$ \\ Ju-Jun Xue \\ Ying-Juan Chang ${ }^{5}$ \\ Xiu-Lin $L v^{6}$ \\ Na Wang ${ }^{7}$ \\ Chen-Yi Sun ${ }^{3}$ \\ Hong Jiang ${ }^{3}$ \\ \# Peng Wang and $X_{i}$ Chen contributed to this paper \\ equally, both as the first authors.
}

\section{Affiliations}

1. Integrated TCM \& Western Medicine Department, Heilongjiang Provincial Hospital, Harbin, 150036, China 2.Department of radioimmunity, Heilongjiang Provincial Hospital, Harbin, 150036, China

3.Department of magnetic resonance imaging, Heilongjiang Provincial Hospital, Harbin, 150036, China 4.Geriatric department of Internal Medicine, Heilongjiang Provincial Hospital , Harbin, 150036, China

5.Central supply room, Heilongjiang Provincial Hospital, Harbin 150036, China

6. Quality Control Office, Heilongjiang Provincial Hospital, Harbin 150036, China

7.Medical Administration Division, Heilongjiang Provincial Hospital, Harbin 150036, China

\section{Corresponding Author}

Hang Zhou

Department of magnetic resonance imaging, Heilongjiang Provincial Hospital, No.82 of Zhongshan Road ,Xiangfang District, Harbin 150036,China - Tel: +86 45187131060 - Fax: +86 451

87131060

E-mail:26276486@qq.com

Fund program: Research project of Heilongjiang provincial health and Family Planning Commission(No. 2016-541), (No:2018416), (No:2019163). 